\title{
Effect of basalt fibres on the parameters of fracture mechanics of MB modifier based high- strength concrete
}

\author{
Makhmud Kharun* and Dmitry Koroteev \\ Peoples' Friendship University of Russia (RUDN University), 117198 Moscow, Russia
}

\begin{abstract}
Basalt fibres (BF) are increasingly studied in structural applications due to its environmental friendliness and good mechanical properties. Mass production of high-strength concrete (HSC) in Russia is mainly associated with the use of organomineral modifiers of the MB series, containing in their composition microsilica, fly ash, hardening regulator and superplasticizer $\mathrm{C}-3$ in different ratios. In our study we produced HSC specimens (without BF, and with 1 wt.\% chopped BF) using the modifier MB10-30, with the dimensions of 100x100x100 mm, 100x100x400 mm, 100x100x400 mm with the artificial crack of $25 \mathrm{~mm}$ deep in the middle of the span, and also $100 \times 75 \times 400 \mathrm{~mm}(75 \mathrm{~mm}$ height was taken equal to the height of the section above the crack of the 2nd type of prisms). The compressive strength, the tensile strength at bending, the strength at axial tension, the cracking moment, and also the parameters of fracture mechanics, such as: the critical stress intensity factor and the critical energy release rate, at the curing periods of 7, 14, 28, 60 days, have been determined. We also evaluated the influence of crack in the bend element on the value of the cracking moment. The results showed that the inclusion of $\mathrm{BF}$ in MB modifier based HSC resulted in a decrease in the compressive strength, however, significantly enhanced its flexure behavior.
\end{abstract}

\section{Introduction}

Basalt fibres (BF) have recently gained popularity in concrete reinforcing applications due to its chemical resistance, environmental friendliness, thermal resistance and good mechanical characteristics. BF reinforced high-strength concrete (HSC) is currently being used in the construction of high-rise buildings, bridges, airport runways and highway pavements.

During the last decade, the research has been carried out on some physical and mechanical properties of BF reinforced concrete and HSC. Some researchers [1,2] revealed that BF can significantly improve the flexural properties of concrete. Branston et al. [3] found that $\mathrm{BF}$ in concrete are effective in preventing cracks by reducing the magnitude of free shrinkage, and by restricting the growth of cracks if they do occur. Ayub, Kizilkanat et al. $[4,5]$ observed that BF reinforced HSC significantly enhance the splitting tensile strength and the critical stress intensity factor. Investigation of High et al. [6] on BF

Corresponding author: miharun@mail.ru 
reinforced concrete revealed that BF addition in concrete significantly enhance its flexural modulus. Kabay [7] established a quite strong relationship between abrasive wear and void content and flexural strength of concretes when adding BF. Experimental study of Jiang et al. [8] showed that adding BF in concrete significantly improves the tensile strength, flexural strength and toughness index.

Pehlivanli et al. [9] studied BF reinforced lightweight autoclaved aerated concrete, and found that the inclusion of $\mathrm{BF}$ in autoclaved aerated concrete increases the flexural and compressive strengths.

Borhan [10] used recycled waste glass sand, as a partial replacement for the natural fine aggregate, with BF in his study. Using BF leads to an enhancement in the compressive and splitting tensile strength. Dong, Katkhuda et al. [11, 12] studied BF reinforced recycled aggregate concrete, and revealed that $\mathrm{BF}$ accumulate in recycled aggregate concrete pores, and also enhance the mechanical properties of recycled aggregate concrete. BF reinforced recycled aggregate concrete can reduce the environmental hazards from a large amount of earthquake waste from collapsed buildings.

Mass production of HSC in Russia is mainly associated with the use of organomineral modifiers of the MB and Embelit series, containing in their composition microsilica, fly ash, hardening regulator and superplasticizer C-3 in different ratios. Many researchers studied the physical and mechanical properties, including the parameters of fracture mechanics of HSC [13, 14], however, the parameters of fracture mechanics of $\mathrm{BF}$ reinforced MB and Embelit modifier based HSC remained unexplored.

The aim of the study is to determine the parameters of fracture mechanics, such as the critical stress intensity factor and the critical energy release rate, and also to evaluate the influence of crack in the bend element on the value of the cracking moment, of HSC produced with the MB modifier.

\section{Materials and methods of research}

Within this study we selected modifier MB10-30C, an admixture on the organomineral basis containing microsilica, fly ash, hardening regulator and superplasticizer $\mathrm{C}-3$, as the basic research material of HSC, which finds an increasing application in the contemporary construction in Russia.

Experimental study of HSC was carried out with the following composition: Portland cement M500 of type I $=500 \mathrm{~kg} / \mathrm{m}^{3}$, concrete modifier MB10-30C $=125 \mathrm{~kg} / \mathrm{m}^{3}$, sand with the fineness modulus of $2.7=585 \mathrm{~kg} / \mathrm{m}^{3}$, crushed granite with the fraction of $5-20 \mathrm{~mm}=$ $1005 \mathrm{~kg} / \mathrm{m}^{3}$, water $=187.5 \mathrm{l} / \mathrm{m}^{3}$, and chopped BF of $12 \mathrm{~mm}$ length for BF reinforced HSC $=$ $24 \mathrm{~kg} / \mathrm{m}^{3}$ (1 wt.\% of HSC).

Experimental study was carried out in accordance with the CIS Interstate Standard GOST 10180-2012 [15].

Within this experimental study we produced total 32 series of test specimens of HSC (without $\mathrm{BF}-16$ series, and with $\mathrm{BF}-16$ series) from the stated composition with dimensions of 100x100x100 mm - 8 series; 100x100x400 mm - 8 series, 100x100x400 $\mathrm{mm}$ with an artificial crack of $25 \mathrm{~mm}$ deep in the middle of the span -8 series, and also $100 \times 75 \times 400 \mathrm{~mm}(75 \mathrm{~mm}$ height was taken equal to the height of the section above the crack of the 2 nd type of prisms) -8 series.

The dimensions of the cross-sections of the prisms were chosen in such a way that the results of the laboratory test could determine the parameters of fracture mechanics, and also assess the influence of the stress concentrator in the form of crack in the tensile zone at the cracking moment. Therefore, the height of the cross-section of the third type of prisms $(100 \times 75 \times 400 \mathrm{~mm})$ was taken equal to the cross-sectional height above the artificial crack in 
the middle of the span of the second type of prisms (100x100x400 mm with an artificial crack of $25 \mathrm{~mm}$ deep in the middle of the span) $-75 \mathrm{~mm}$.

In accordance with the plan of experiment, each series consists of 3 specimens, 12 in every type, total 96 specimens. All specimens were cured in air-humid condition in wet sawdust at the room temperature of $19-22{ }^{\circ} \mathrm{C}$.

Laboratory tests were carried out at the curing periods of $7,14,28,60$ days on a hydraulic press of up to $1500 \mathrm{kN}$ at the compression test, and up to $150 \mathrm{kN}$ at the bending test.

Compressive strength $R_{c}$ and tensile strength at bending $R_{c t}$ were identified in accordance with GOST 10180-2012 [15].

Strength at axial tension $R_{c t f}$ and cracking moment $M_{c r c}$ were determined by the formulas according to SP 63.13330.2012 [16].

Critical stress intensity factor $K_{I c}$ and critical energy release rate $G_{I c}$ were identified in accordance with GOST 10180-2012 and GOST 24452-80 [15, 17].

\section{Results and discussions}

The most important physical and mechanical properties of concrete are the compressive strength, the tensile strength at bending, the strength at axial tension and the cracking moment.

In addition, in order to assess the load-bearing capacity of the reinforced concrete structures from the position of fracture mechanics, the characteristics of the crack resistance of concrete are important, particularly: the critical stress intensity factor and the critical energy release rate.

In the framework of this study we carried out the experimental determination of the compressive strength, the tensile strength at bending, the strength at axial tension and the cracking moment, as well as the characteristics of the crack resistance: the critical stress intensity factor and the critical energy release rate of HSC produced with modifier MB10$30 \mathrm{C}$ without $\mathrm{BF}$ and with $1 \mathrm{wt} . \%$ chopped $\mathrm{BF}$.

The following types of test specimens were examined:

1. 8 series of specimens (without $\mathrm{BF}-4$ series, and with 1 wt. $\% \mathrm{BF}-4$ series) of $100 \times 100 \times 100 \mathrm{~mm}$ of cube shape were tested to determine the compressive strength (Table $1)$.

2. 8 series of specimens (without BF -4 series, and with 1 wt. $\%$ BF -4 series) of 100x 100x400 mm of prism shape were tested to determine the tensile behavior (Table 2).

3. 8 series of specimens (without $\mathrm{BF}-4$ series, and with 1 wt. $\% \mathrm{BF}-4$ series) of 100x100x400 mm of prism shape with artificial crack of $25 \mathrm{~mm}$ deep in the middle of the span were tested to determine the tensile behavior, as well as parameters of fracture mechanics (Table 3).

4. 8 series of specimens (without $\mathrm{BF}-4$ series, and with 1 wt. $\% \mathrm{BF}-4$ series) of $100 \times 75 \times 400 \mathrm{~mm}$ of prism shape were tested to determine the tensile behavior for comparison with samples with artificial crack (Table 4).

Fig. 1 shows the diagrams of changes in compressive strength of HSC depending on the curing period.

Analysis of the diagrams of the Fig. 1 shows that the strength growth in HSC specimens is smooth and uniform as in conventional concrete regardless of whether HSC is without $\mathrm{BF}$ or with BF. 
Table 1. Results of the laboratory tests of HSC specimens of 100x100x100 mm on the compressive strength

\begin{tabular}{|c|c|c|}
\hline Curing period, Days & $\begin{array}{c}\text { Average } R_{c} \text { of HSC specimens } \\
\text { without BF, MPa }\end{array}$ & $\begin{array}{c}\text { Average } R_{c} \text { of HSC specimens with } \\
1 \% \mathrm{BF}, \mathrm{MPa}\end{array}$ \\
\hline 7 & 69.68 & 56.73 \\
\hline 14 & 86.45 & 69.86 \\
\hline 28 & 100.23 & 80.52 \\
\hline 60 & 102.72 & 82.21 \\
\hline
\end{tabular}

Table 2. Results of the laboratory tests of HSC specimens of 100x100x400 mm on the tensile behavior

\begin{tabular}{|c|c|c|c|c|c|c|}
\hline \multirow{2}{*}{$\begin{array}{c}\text { Curing } \\
\text { period, } \\
\text { Days }\end{array}$} & \multicolumn{3}{|c|}{ HSC specimens without BF } & \multicolumn{3}{c|}{ HSC specimens with 1\% BF } \\
\cline { 2 - 7 } & $\begin{array}{c}\text { Average } R_{c t}, \\
\text { MPa }\end{array}$ & $\begin{array}{c}\text { Average } R_{c t f}, \\
\text { MPa }\end{array}$ & $\begin{array}{c}\text { Average } M_{c r c}, \\
\text { N.m }\end{array}$ & $\begin{array}{c}\text { Average } R_{c t}, \\
\text { MPa }\end{array}$ & $\begin{array}{c}\text { Average } R_{c t f}, \\
\text { MPa }\end{array}$ & $\begin{array}{c}\text { Average } M_{c r c}, \\
\text { N.m }\end{array}$ \\
\hline 7 & 6.73 & 3.84 & 1099.46 & 9.83 & 5.60 & 1605.21 \\
\hline 14 & 7.19 & 4.12 & 1216.80 & 10.35 & 5.93 & 1752.19 \\
\hline 28 & 7.57 & 4.32 & 1236.69 & 11.13 & 6.35 & 1817.93 \\
\hline 60 & 8.16 & 4.66 & 1332.80 & 11.99 & 6.85 & 1959.21 \\
\hline
\end{tabular}

Table 3. Results of the laboratory tests on the tensile behavior of HSC specimens of 100x100x400 $\mathrm{mm}$ with artificial crack of $25 \mathrm{~mm}$ deep in the middle of the span

\begin{tabular}{|c|c|c|c|c|c|}
\hline $\begin{array}{c}\text { Curing } \\
\text { period, } \\
\text { Days }\end{array}$ & $\begin{array}{c}\text { Average } R_{c t}, \\
\text { MPa }\end{array}$ & $\begin{array}{c}\text { Average } R_{c t f}, \\
\text { MPa }\end{array}$ & $\begin{array}{c}\text { Average } M_{c r c}, \\
\text { N.m }\end{array}$ & $\begin{array}{c}\text { Average } K_{I c}, \\
\text { MPa } \mathrm{m}^{0.5}\end{array}$ & $\begin{array}{c}\text { Average } G_{I c}, \\
\mathrm{~N} / \mathrm{m}\end{array}$ \\
\hline 7 & 5.89 & 3.37 & 543.31 & 0.599 & 9.624 \\
\hline 14 & 6.36 & 3.54 & 599.76 & 0.633 & 10.270 \\
\hline 28 & 6.51 & 3.72 & 646.90 & 0.649 & 10.408 \\
\hline 60 & 6.90 & 3.94 & 659.54 & 0.657 & 10.574 \\
\hline \multicolumn{5}{|c|}{ HSC specimens with 1\% BF } \\
\hline 7 & 8.66 & 4.95 & 798.66 & 0.881 & 14.147 \\
\hline 14 & 9.16 & 5.10 & 863.63 & 0.912 & 14.789 \\
\hline 28 & 9.51 & 5.43 & 944.45 & 0.948 & 15.196 \\
\hline 60 & 9.87 & 5.63 & 953.14 & 0.959 & 15.221 \\
\hline
\end{tabular}

Table 4. Results of the laboratory tests of HSC specimens of $100 \times 75 \times 400 \mathrm{~mm}$ on the tensile behavior

\begin{tabular}{|c|c|c|c|c|c|c|}
\hline \multirow{2}{*}{$\begin{array}{c}\text { Curing } \\
\text { period, } \\
\text { Days }\end{array}$} & \multicolumn{3}{|c|}{ HSC specimens without BF } & \multicolumn{3}{c|}{ HSC specimens with 1\% BF } \\
\cline { 2 - 7 } & $\begin{array}{c}\text { Average } R_{c t}, \\
\text { MPa }\end{array}$ & $\begin{array}{c}\text { Average } R_{c t f}, \\
\text { MPa }\end{array}$ & $\begin{array}{c}\text { Average } M_{c r c}, \\
\text { N.m }\end{array}$ & $\begin{array}{c}\text { Average } R_{c t}, \\
\text { MPa }\end{array}$ & $\begin{array}{c}\text { Average } R_{c t f}, \\
\text { MPa }\end{array}$ & $\begin{array}{c}\text { Average } M_{c r c}, \\
\text { N.m }\end{array}$ \\
\hline 7 & 6.48 & 3.69 & 578.56 & 9.39 & 5.35 & 838.91 \\
\hline 14 & 6.73 & 3.85 & 607.62 & 9.62 & 5.51 & 868.89 \\
\hline 28 & 7.07 & 4.07 & 653.88 & 10.39 & 5.98 & 961.20 \\
\hline 60 & 7.40 & 4.22 & 685.09 & 10.80 & 6.16 & 1000.23 \\
\hline
\end{tabular}

Study of our HSC specimens (Table 1 and Fig. 1) showed that addition of BF in HSC resulted in a decrease in the compressive strength about $18-20 \%$. The results also showed that the compressive strength in 7 days of curing can reach about $70 \%$ of the compressive strength of 28 days curing period regardless of whether HSC is without BF or with BF.

Diagrams of Fig. 2, 3 and 4 show the kinetics of the tensile behavior of HSC depending on the curing period.

Analyzing the diagrams in Fig. 2, 3 and 4, and the Tables 2, 3 and 4, it can be concluded that HSC with 1 wt.\% BF enhance the tensile behavior about $42-48 \%$. The results of laboratory tests also showed that, regardless of whether HSC is without BF or with BF,

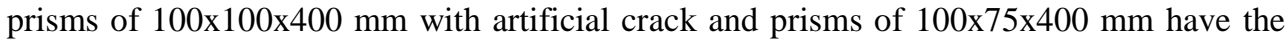


same cross sectional height in the middle of the span, however, due to the presence of artificial crack, the tensile strength at bending, and the strength at axial tension decrease by an average of $8 \%$.

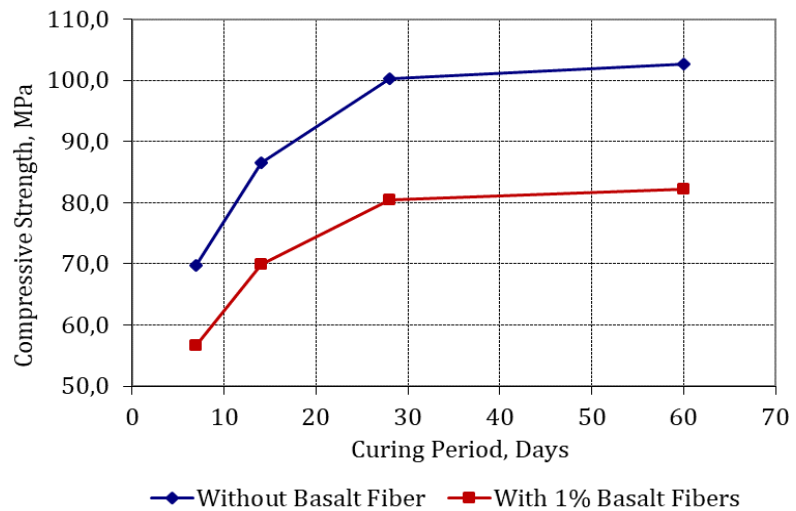

Fig. 1. Compressive strength of HSC depending on the curing period of HSC specimens of $100 \times 100 \times 100 \mathrm{~mm}$

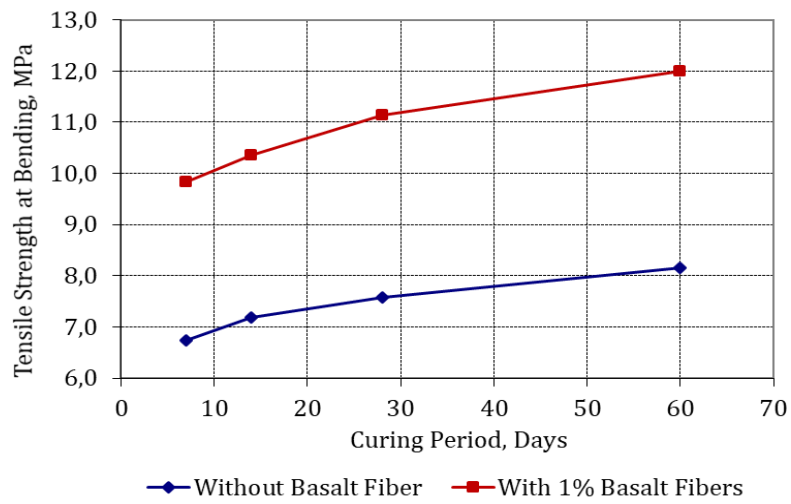

Fig. 2. Tensile strength at bending of HSC depending on the curing period of HSC specimens of $100 \times 100 \times 400 \mathrm{~mm}$

After studying the three types of HSC prisms (without BF, and with $1 \mathrm{wt} . \% \mathrm{BF}$ ) it can be stated that, regardless of whether HSC is without BF or with BF, the tensile strength of concrete was distributed as follows: crack;

- the greatest strength is possessed by prisms of $100 \times 100 \times 400 \mathrm{~mm}$ without any artificial

- the strength of prisms of $100 \times 75 \times 400 \mathrm{~mm}$ without artificial crack is reduced by an average of $6 \%$ due to a decrease in the cross-sectional height by $25 \mathrm{~mm}$;

- the strength of prisms of $100 \times 100 \times 400 \mathrm{~mm}$ with an artificial crack in the middle of the span is reduced by an average of $14 \%$ due to the presence of the stress concentrator in the form of an artificial crack of $25 \mathrm{~mm}$ deep.

In our research we also planned to examine the two factors, the reduction of height of the cross-section of the bending element and the presence of an artificial crack in the tensile zone, to what extent these two factors affect the decrease in the cracking moment. Analysing the tables 2, 3 and 4, the following conclusions can be drawn, regardless of whether HSC is without BF or with BF:

- the decrease in the cross-sectional height by 0.25 reduces the cracking moment by an average of $42-46 \%$; 
- the presence of a stress concentrator in the form of an artificial crack with the depth of 0.25 of the cross-sectional height in the tensile zone reduces the cracking moment by an average of $48-50 \%$.

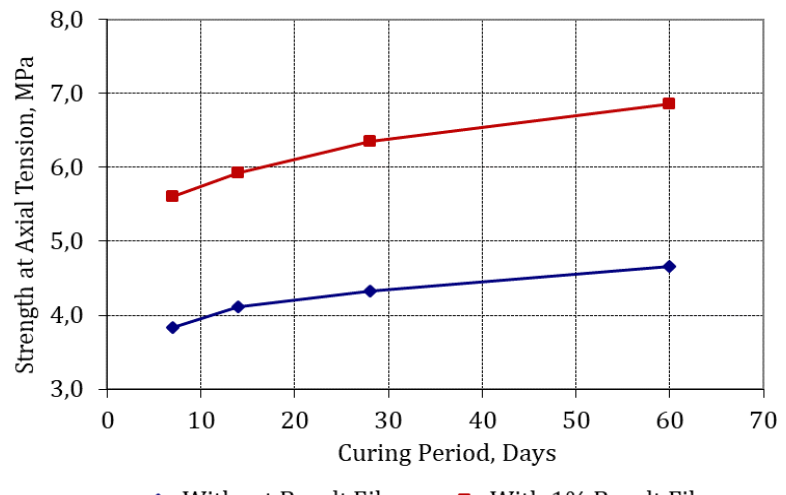

Fig. 3. Strength at axial tension of HSC depending on the curing period of HSC specimens of $100 \times 100 \times 400 \mathrm{~mm}$

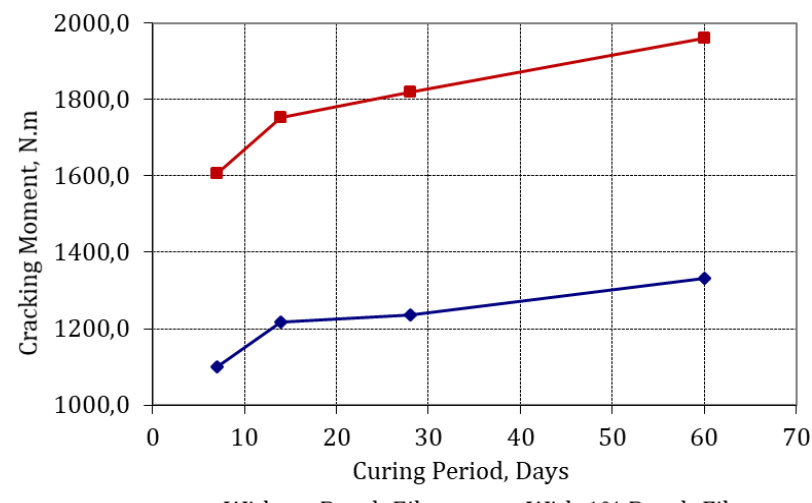

$\rightarrow$ Without Basalt Fiber $\rightarrow$-With 1\% Basalt Fibers

Fig. 4. Cracking moment of HSC depending on the curing period of HSC specimens of 100x 100x400 $\mathrm{mm}$

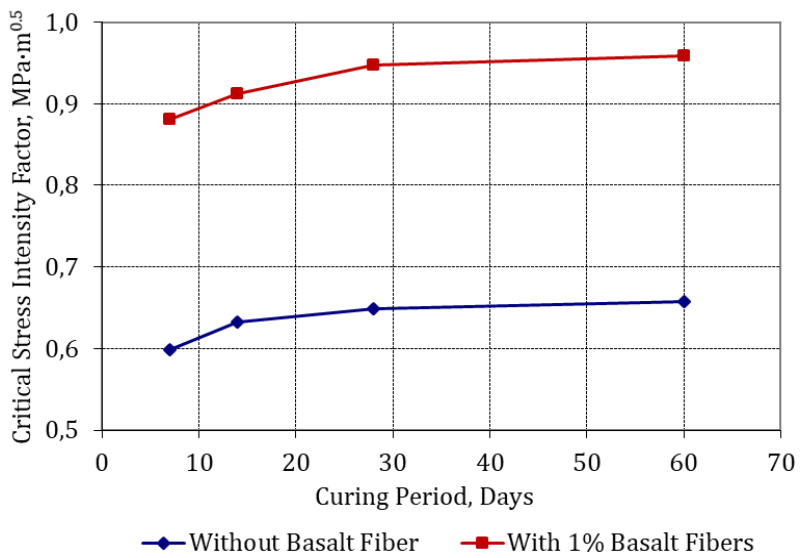

Fig. 5. Critical stress intensity factor of HSC depending on the curing period of HSC specimens of $100 \times 100 \times 400 \mathrm{~mm}$ 


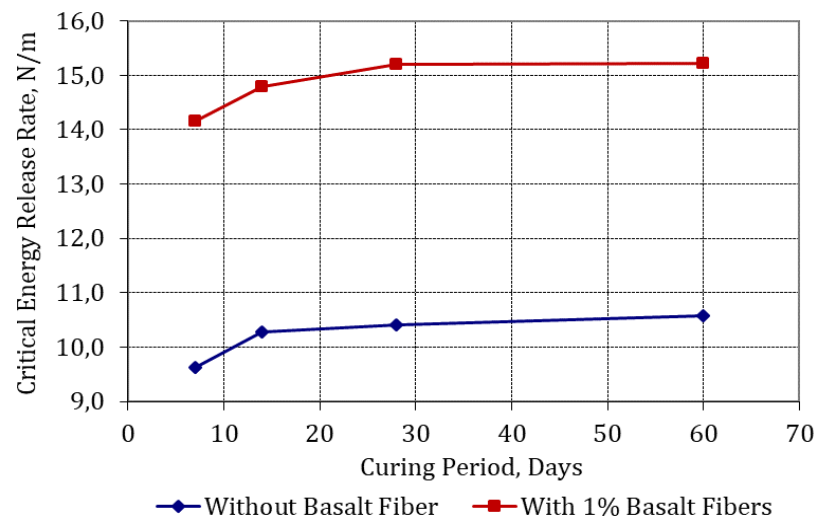

Fig. 6. Critical energy release rate of HSC depending on the curing period of HSC specimens of $100 \times 100 \times 400 \mathrm{~mm}$

Fig. 5 and 6 show the dependency of the critical stress intensity factor and the critical energy release rate on the curing period of HSC with crack.

Analysis of Fig. 1-6 and Tables 1-4 shows that the parameters of fracture mechanics including the physical and mechanical properties of HSC produced with modifier MB10$30 \mathrm{C}$, regardless of whether $\mathrm{HSC}$ is without BF or with BF, intensely grow during the first 7 days, and are smooth and uniform as in conventional concrete.

Our study revealed that the addition of $1 \mathrm{wt} . \%$ BF in HSC resulted in a decrease in the compressive strength about $18-20 \%$, however, enhance the flexure behavior about $42-48 \%$. In addition, experimental study of HSC specimens shows that HSC without BF is more brittle than with BF.

\section{Conclusion}

On the basis of the experimental study of HSC produced with the modifier MB10-30C, without $\mathrm{BF}$ and with $1 \mathrm{wt} . \% \mathrm{BF}$, the following parameters were identified:

1. The physical and mechanical properties, such as the compressive strength, the tensile strength at bending, the strength at axial tension, and the cracking moment.

2. The parameters of fracture mechanics, such as the critical stress intensity factor and the critical energy release rate, and also their dependency on the curing period.

3. The influence of crack in the bend element on the value of the cracking moment.

Experimental study of HSC produced with the modifier MB10-30C, without BF and with 1 wt.\% BF, showed that:

1. The addition of $1 \mathrm{wt} . \% \mathrm{BF}$ in HSC decreases the compressive strength about $18-20 \%$.

2. HSC with 1 wt. $\%$ BF enhance the flexure behavior about $42-48 \%$.

3. The addition of BF in HSC reduces brittleness.

\section{References}

1. A. Sadrmomtazi, B. Tahmouresi, A. Saradar, Construction and Building Materials, 162, 321-333 (2018)

2. M. Afroz, I. Patnaikuni, S. Venkatesan, Construction and Building Materials, 154, 191203 (2017)

3. J. Branston, S. Das, S.Y. Kenno, C. Taylor, Cement and Concrete Composites, 74, 182190 (2016)

4. T. Ayub, N. Shafiq, M.F. Nuruddin, Procedia Engineering, 77, 131-139 (2014) 
5. A.B. Kizilkanat, N. Kabay, V. Akyüncü, S. Chowdhury, A.H. Akça, Construction and Building Materials, 100, 218-224 (2015)

6. C. High, H.M. Seliem, A. El-Safty, S.H. Rizkalla, Construction and Building Materials, 96, 37-46 (2015)

7. N. Kabay, Construction and Building Materials, 50, 95-101 (2014)

8. C. Jiang, K. Fan, F. Wu, D. Chen, Materials \& Design, 58, 187-193 (2014)

9. Z.O. Pehlivanl1, İ. Uzun, İ. Demir, Construction and Building Materials, 96, 428-433 (2015)

10. T.M. Borhan, Materials \& Design, 42, 265-271 (2012)

11. J.F. Dong, Q.Y. Wang, Z.W. Guan, Construction and Building Materials, 130, 241-251 (2017)

12. H. Katkhuda, N. Shatarat, Construction and Building Materials, 140, 328-335 (2017)

13. S.S. Kaprielov, A.V. Sheynfeld, D. Al-Omais, A.S. Zaitsev, Promyshlennoe i Grazhdanskoe Stroitelstvo [Industrial and Civil Engineering], 3, 53-57 (2017), Available online at: https://elibrary.ru/item.asp?id=28868869

14. N.I. Karpenko, A.V. Mishina, V.I. Travush, Procedia Engineering, 111, 390-397 (2015)

15. GOST 10180-2012, Betony. Metody opredeleniya prochnosti po kontrolnym obraztsam [Concretes. Methods for determination of strength by control samples], (Standartinform Publisher, Moscow, Russia, 2013), Available online at: http://gostexpert.ru/gost/gost10180-2012

16. SP 63.13330.2012, Betonnyye i zhelezobetonnyye konstruktsii. Osnovnyye polozheniya [Concrete and reinforced concrete structures. Basic provisions], (Ministry of Regional Development of the Russian Federation, Moscow, Russia, 2015), Available online at: http://docs.cntd.ru/document/1200095246

17. GOST 24452-80, Betony. Metody opredeleniya prizmennoy prochnosti, modulya uprugosti i koeffitsiyenta Puassona [Concretes. Methods for determination of prismatic strength, modulus of elasticity and Poisson's ratio], (Standartinform Publisher, Moscow, Russia, 2005) Available online at: http://gostexpert.ru/gost/gost-24452-80 